\title{
Fluid Biomarkers for Monitoring Structural Changes in Polyneuropathies: Their Use in Clinical Practice and Trials
}

\author{
Luuk Wieske $^{1} \cdot$ Duncan Smyth ${ }^{2,3} \cdot$ Michael P. Lunn $^{2,3} \cdot$ Filip Eftimov $^{1} \cdot$ Charlotte E. Teunissen $^{4}$
}

Accepted: 29 September 2021 / Published online: 18 October 2021

(c) The Author(s) 2021, corrected publication 2021

\begin{abstract}
Reliable and responsive tools for monitoring disease activity and treatment outcomes in patients with neuropathies are lacking. With the emergence of ultrasensitive blood bioassays, proteins released with nerve damage are potentially useful response biomarkers for many neurological disorders, including polyneuropathies. In this review, we provide an overview of the existing literature focusing on potential applications in polyneuropathy clinical care and trials. Whilst several promising candidates have been identified, no studies have investigated if any of these proteins can serve as response biomarkers of longitudinal disease activity, except for neurofilament light (NfL). For NfL, limited evidence exists supporting a role as a response biomarker in Guillain-Barré syndrome, vasculitic neuropathy, and chronic inflammatory demyelinating polyradiculoneuropathy (CIDP). Most evidence exists for NfL as a response biomarker in hereditary transthyretin-related amyloidosis (hATTR). At the present time, the role of NfL is therefore limited to a supporting clinical tool or exploratory endpoint in trials. Future developments will need to focus on the discovery of additional biomarkers for anatomically specific and other forms of nerve damage using high-throughput technologies and highly sensitive analytical platforms in adequality powered studies of appropriate design. For NfL, a better understanding of cut-off values, the relation to clinical symptoms and long-term disability as well as dynamics in serum on and off treatment is needed to further expand and proceed towards implementation.
\end{abstract}

Keywords Biomarkers $\cdot$ Nerve damage $\cdot$ Polyneuropathies $\cdot$ Neurofilament light chain

\section{Introduction}

Polyneuropathies have a total prevalence of about $1 \%$ in the unselected population, and up to $7 \%$ in elderly [1]. There are many causes of polyneuropathy, the most frequent being diabetes mellitus, alcohol overuse, nutritional deficiencies, toxins and medication, genetic causes, and autoimmune and haematological disorders, whilst infections, in particular leprosy, are a more frequent cause in lower income countries. In

Charlotte E. Teunissen

c.teunissen@amsterdamumc.nl

1 Department of Neurology and Neurophysiology, Amsterdam Neuroscience, Amsterdam UMC, Location AMC, Amsterdam, the Netherlands

2 Centre for Neuromuscular Disease, National Hospital for Neurology and Neurosurgery, London, UK

3 UCL Queen Square Institute of Neurology, London, UK

4 Neurochemistry Lab, Department of Clinical Chemistry, Amsterdam Neuroscience, Amsterdam UMC, Vrije Universiteit, Amsterdam, the Netherlands around $20-30 \%$ of cases, the polyneuropathy has no identified cause and is idiopathic [2]. Typically, the diagnosis of a polyneuropathy is based on the clinical pattern of history and examination in combination with nerve conduction studies, while laboratory testing and other ancillary tests may be needed to clarify or confirm a potential cause that may or may not be amenable to treatment.

Arguably, the most important unmet need in the field is the monitoring of disease activity and treatment response in patients with treatable neuropathies such as chronic inflammatory demyelinating polyradiculoneuropathy (CIDP), hereditary transthyretin-related amyloidosis (hATTR), and anti-MAG neuropathy. Nerve conduction studies can be poorly tolerated by patients and are also poorly responsive to change, especially in patients with severe axonal damage. Nerve imaging with ultrasound or MRI in the twenty-first century has improved resolution, but with low specificity and inconsistent reliability when used as a response biomarker limits utility [3]. Therefore, clinical disease activity measures currently employed in clinical care and trials are mostly based on clinical outcomes such as measuring 
(patient reported) disability, muscle strength, and sensory deficits through clinical examination (impairments) or patient reported measures of disability. Unfortunately, a reliance solely on clinical assessment has drawbacks. In the presence of severe axonal damage (for example, in vasculitic neuropathy, severe Guillain-Barré syndrome (GBS), and paranodopathies), clinical improvement can be very delayed. In other neuropathies (for example, anti-MAG neuropathy or genetic neuropathies), progression might be too slow to capture change with clinical outcome measures, making clinical decisions difficult and clinical interventional studies very prolonged. In these patients, it would be very useful to have an early biochemical response biomarker to determine whether they are receiving optimal treatment and are likely to obtain later improvement. Finally, clinical outcomes cannot discern ongoing from residual damage and in some patients, such as those receiving maintenance intravenous immunoglobulin (IVIg) treatment for CIDP; identifying relapse or stability may avoid trial-and-error treatment withdrawal attempts, and unnecessary treatment re-initiations.

The recent development of high-sensitivity techniques to measure fluid biomarkers has accelerated biomarker research in polyneuropathies. There have recently been several reports on how biomarkers could potentially improve and accelerate diagnosis but also allow for assessment of disease activity. Most have focused on non-specific biomarkers of disease activity reflecting nerve damage. In this review, we will provide an overview of biomarker candidates that reflect structural damage across different types of neuropathies, with a focus on diagnostic and response biomarkers [4]. In particular, we will focus on neurofilament light chain (NfL) in blood as a response biomarker of disease activity in different neuropathies. Finally, we will share our view on their use in clinical care and clinical studies and future perspectives in biomarker development.

\section{Fluid Nerve Damage Biomarkers: What Is Known in Peripheral Nerve Disease?}

At least three important challenges exist for damage biomarkers in neuropathies. Firstly, peripheral nerve tissue is of low volume and nerve-specific proteins are usually only present in very low concentrations in blood. Secondly, the tempo of damage can be acute or more importantly very prolonged, which when combined with biomarker pharmacokinetics means levels can be even lower. Therefore, assays need to have sufficient sensitivity to detect very low circulating levels. Thirdly, nerve structures, like myelin, axon, or paranode, may be preferentially or even exclusively damaged in different disorders. Therefore, it is likely that different biomarkers reflecting different nerve components are needed. While one would prefer high specificity for a diagnostic biomarker, in general response biomarkers do not need to be so specific as long as they have sufficient sensitivity and responsiveness (that is, it will closely follow changes in disease activity). Below, we have summarized biomarkers reflecting damage to different nerve structures (Table 1).

\section{Myelin Biomarkers}

While the numerous lipids and proteins within Schwann cells and the myelin sheath are now well-characterized [5], there are currently few useful fluid biomarkers of demyelination. To date, three have shown some initial promise as biomarkers. Extracellular sphingomyelin, a widely distributed sphingolipid of the myelin sheath in peripheral and central nerves, can be measured. CSF sphingomyelin was higher in acute inflammatory demyelinating polyneuropathy (AIDP) and CIDP than in various non-inflammatory neurological disorders and axonal neuropathies including the acute motor axonal neuropathy (AMAN) variant of GBS. There was some overlap between groups, although sphingomyelin still showed relatively good sensitivity and high specificity for differentiating AIDP/active CIDP from other neurological disorders [6, 7]. Levels also correlated with clinical severity scores in both AIDP and CIDP [6]. While sphingomyelin shows promise as a diagnostic and possibly prognostic biomarker, the results need to be replicated in other studies.

Neural cell adhesion molecule (NCAM) is a member of the immunoglobulin superfamily expressed on several different neural cell types including Schwann cells. In one study, the mean serum NCAM levels were higher in demyelinating neuropathies (both inflammatory and Charcot-Marie-Tooth disease (CMT) type 1A) than in healthy controls and axonal neuropathies, and there was a positive correlation with the Overall Neuropathy Limitations Score [8]. NCAM levels were also raised, but to a lesser extent, in axonal neuropathies compared to healthy controls, and there was significant overlap between demyelinating and axonal groups, probably limiting its use as a diagnostic biomarker [8].

Serum levels of p75 neurotrophin receptor, a transmembrane protein expressed on Schwann cells and some CNS neurons, were raised in inflammatory demyelinating neuropathies but not in CMT1A, whereas NCAM levels were raised in both, indicating that there may be potential to use the levels of NCAM and p75 to differentiate CIDP from CMT in difficult cases, with a raised p75 differentiating CIDP from CMT1A with both high sensitivity and specificity [9]. The high serum levels of NCAM and p75 have been postulated to reflect increased expression by demyelinating Schwann cells and thus may not change very rapidly in acute disease.

Transmembrane protease serine 5 (TMPRSS5), a transmembrane protein expressed on Schwann cells, was 
identified in one study as capable of discriminating between CMT subtypes, with CMT1A patients showing increased serum levels whereas other forms of CMT did not have elevated levels [10].

\section{Axonal Biomarkers}

The axonal cytoskeleton is made from a small number of repeating co-associating proteins, and these can be released to the extracellular space by axonal damage. By far, the best studied axonal damage markers in neurological diseases is $\mathrm{NfL}$. NfL is a ubiquitous cytoskeletal protein and released into the CSF and blood in numerous CNS disorders and peripheral neuropathies (see further below). Although neurofilament heavy $(\mathrm{NfH})$ was described as an axonal biomarker well before $\mathrm{NfL}$ and early studies of small numbers of patients showed that higher CSF levels predict axonal involvement and poor outcome in GBS [11-13], it has not been as extensively studied. Subsequent investigators described that serum $\mathrm{NfH}$ levels were higher in diabetic neuropathy than in diabetics without neuropathy [14], and plasma levels were higher in critical illness neuropathy/ myopathy (CINM) compared to other intensive care patients [15]; once again, in these studies, there was significant overlap in $\mathrm{NfH}$ levels between groups. In contrast to recent $\mathrm{NfL}$ data, $\mathrm{NfH}$ was not higher in CMT compared to healthy controls [16].

The neurotrophins nerve growth factor (NGF) and brainderived neurotrophic factor (BDNF) have been studied in diabetic neuropathy and chemotherapy-induced peripheral neuropathy (CIPN), with higher levels postulated to have a neuroprotective effect. While most studies found that lower levels of neurotrophins correlated with neuropathy and its severity [17-23], the opposite result was found in other studies [24-26], and thus, the utility of neurotrophins as biomarkers remains unclear.

Glial fibrillary acidic protein (GFAP) is an intermediate filament expressed by astrocytes in the CNS and by non-myelinating Schwann cells in the PNS. GFAP is thought to be upregulated in Schwann cells after axonal injury, and thus may be an indirect marker of axonal damage [27]. One research group found that serum GFAP was higher in axonal compared to demyelinating neuropathies; however, there was significant overlap between groups; levels were much higher in patients with multiple sclerosis than in neuropathies $[27,28]$. Increased GFAP levels in CSF and serum have also been seen in GBS; however, there have been conflicting results on whether GFAP can predict long-term outcome [12, 27, 29], and whether it can differentiate AMAN from AIDP [27, 30]. Recently, serum GFAP levels were found to be higher in
COVID-19-associated CINM than other critically unwell COVID-19 patients [31].

S-100B is another glial protein expressed in CNS glial cells and Schwann cells, though unlike GFAP it is found in both myelinating and non-myelinating Schwann cells [32]. S-100B levels have been found to be elevated in GBS $[12,13,33]$, and levels correlated with time to recovery in one study [33] and GBS Disability Scale at 3-4 weeks in another [13]. However, levels did not predict longer term prognosis $[12,13]$ and could not differentiate AIDP from AMAN [13]. S-100B has not been studied in other neuropathies. As evidence on the potential to discriminate between axonal and demyelinating neuropathies is conflicting for both of these glial proteins, it remains uncertain which type(s) of structural nerve damage these biomarkers reflect.

Osteopontin is a widely expressed protein also found in Schwann cells, and is involved in inflammation and possibly axonal regeneration [34]. One study found lower serum levels at baseline that were weakly correlated with reduced sural nerve amplitude and worse clinical outcome after taxane chemotherapy; however, there was a large amount of overlap between groups [35]. In contrast, higher CSF levels of osteopontin were found in patients with GBS, with higher levels correlated with greater disability in the acute phase [36].

For disorders such as sensory neuronopathies, and infectious and inflammatory polyradiculopathies, damage to the neuronal cell body may occur at an early stage of disease. Although the axon and neuron are a continuum, and neuronal damage subsequently leads to axonal damage, some authors have advocated that neuronal proteins such as total tau may be used as markers for neuronal damage [37]. Tau and neuron-specific enolase (NSE), another neuronal protein, have both been studied in GBS, with CSF levels of tau associated with worse short- and medium-term outcome [12,13], and CSF levels of NSE [33] correlated with increased time to recovery [33]. In a recent small study, there was no clear difference between plasma tau levels in COVID-19-positive CINM patients and other critically unwell COVID-19 patients at different timepoints [31].

In summary, for most of the molecules above, variations of study design and overlap between groups make it difficult to say whether any of them are reliable disease overarching diagnostic biomarkers (see Table 1). Most importantly, no study has focused on the potential of these molecules to serve as response biomarkers of disease activity by conducting longitudinal studies in treatable polyneuropathies. However, with the increasing availability of proteomic panels, many more potential biomarkers will likely become available in the coming years. 


\section{Neurofilament Light Chain as a Monitoring Biomarker in Peripheral Nerve Disease}

$\mathrm{NfL}$ is a ubiquitous axonal cytoskeletal protein present in PNS and CNS axons which forms heterodimers with the other neurofilaments alpha-internexin and peripherin [38]. Neurofilament proteins are released with other proteins into interstitial fluid during axonal damage. They can diffuse between CSF and blood, as shown by the strong correlation between levels in the serum and CSF [39]. Its potential as a CSF biomarker was shown in several CNS diseases [40]. However, since the emergence of ultrasensitive technologies enabling its detection at very low levels and in the blood, the number of neurological diseases, including neuropathies, where increased NfL is found has expanded enormously [39].

NfL is currently the best candidate as an axonal damage biomarker for a number of reasons. It is present at high level in axons, and is soluble and stable in vitro [39]. For example, NfL appears insensitive to most variations in pre-analytical handling [41]. However, there are some recovery issues with collection tubes and levels of NfL from lithium-heparin collection tubes are systematically higher than for plasma EDTA serum or citrated samples [42]. Serum and plasma NfL are both stable at room temperature for up to 7 days, and NfL is also stable to up to 4 freeze-thaw cycles and centrifugations [41, 43].

Several platforms have been developed to facilitate measurement of NfL. Serum and plasma levels are in picogrammes per millilitre in normal controls and only slightly higher in more chronic pathological processes. The majority of platforms use the antibody developed by Uman Diagnostics Measurement. Platforms vary in sensitivity (in order of decreasing sensitivity: Simoa-Ella-Siemens), their degree of automation (specialized stand-alone technologies such as Simoa and Ella vs fully clinical chemistry automates linked to robots, such as Siemens and Roche), and the platform costs. Standardization across labs and platforms is the subject of several initiatives, such as the Alzheimer's Association Quality Control Program and BloodBased Biomarker Working Interest Group. The development of reference material and methods is an important unmet need, to allow comparison between different platforms and assay formats and the development of unified cut-offs. There is a strong relationship between NfL levels and age, which means that cross-sectional results should always be compared against reference values obtained in the same age groups [39].

$\mathrm{NfL}$ levels can increase rapidly (within $12 \mathrm{~h}$ after hypoxic cardiac arrest [44]) and decline slowly, with an estimated half-life of 6 weeks. In vivo decline corresponding with intervention efficacy has been shown to occur within 12 weeks in multiple sclerosis patients treated with ocrelizumab $[45,46]$.
An overview of studies investigating NfL in neuropathies is provided in Table 2. Increased blood or CSF NfL levels compared to healthy controls have been found in nearly all disorders investigated. However, for many disorders, the data are limited by small numbers, unbalanced control groups (especially for age), variation in analytical platforms and methods, and limited replication. Figure 1 summarizes the relative quantitative change in $\mathrm{NfL}$ for various disorders compared to healthy controls. In GBS, increased blood and/or CSF NfL at the moment of diagnosis was found to predict poor outcome [29, 47]. During a 6-month course of oxaliplatin, NfL levels rose and mirrored disease severity of chemotherapy-induced polyneuropathy [48]. In CIDP, increased group NfL levels were not consistently found across studies when comparing untreated and treated patients, probably because axonal damage is not a prominent feature in all forms of CIDP [49-51]. Indeed, in neurofascin-155-mediated CIDP, NfL levels were higher compared to other forms [49]. The evidence supporting the role of $\mathrm{NfL}$ as a response biomarker of disease activity in neuropathies is limited. When NfL is increased in CIDP, successful treatment can lead to normalization at follow-up $[49,51]$. In patients with vasculitic neuropathy, NfL reduces markedly from a peak when disease remission is achieved [52]. In a clinical trial investigating patisiran for hATTR polyneuropathy, increased NfL levels at enrolment significantly lowered during treatment while NfL levels in the placebo group continued to rise [53].

\section{Neurofilament Light Chain: Perspectives on Current Use in Practice and Trials}

Taken together, only a handful of candidates of nerve tissue biomarkers have been explored in neuropathies. NfL has been studied most and has potential uses in clinical practice and trials. Although there is some way to go in development, we are now at an important juncture for exploring clinical applications.

\section{NfL in Clinical Practice}

$\mathrm{NfL}$ is released in measurable amounts in any disorder where axonal degeneration occurs fast enough to exceed clearance. Where this occurs in a large tissue mass, released into a small volume of fluid and the axon loss is rapidly occurring, this is straightforward; for example, in prion disease and other rapidly progressive dementias, CSF NfL levels are in nanogrammes per millilitre [54]. Significantly raised levels are detectable in the blood, but usually 200-fold lower and still well-discernible from healthy controls. High levels do not necessarily correlate with other established axonal damage biomarkers (for example tau) and are not 


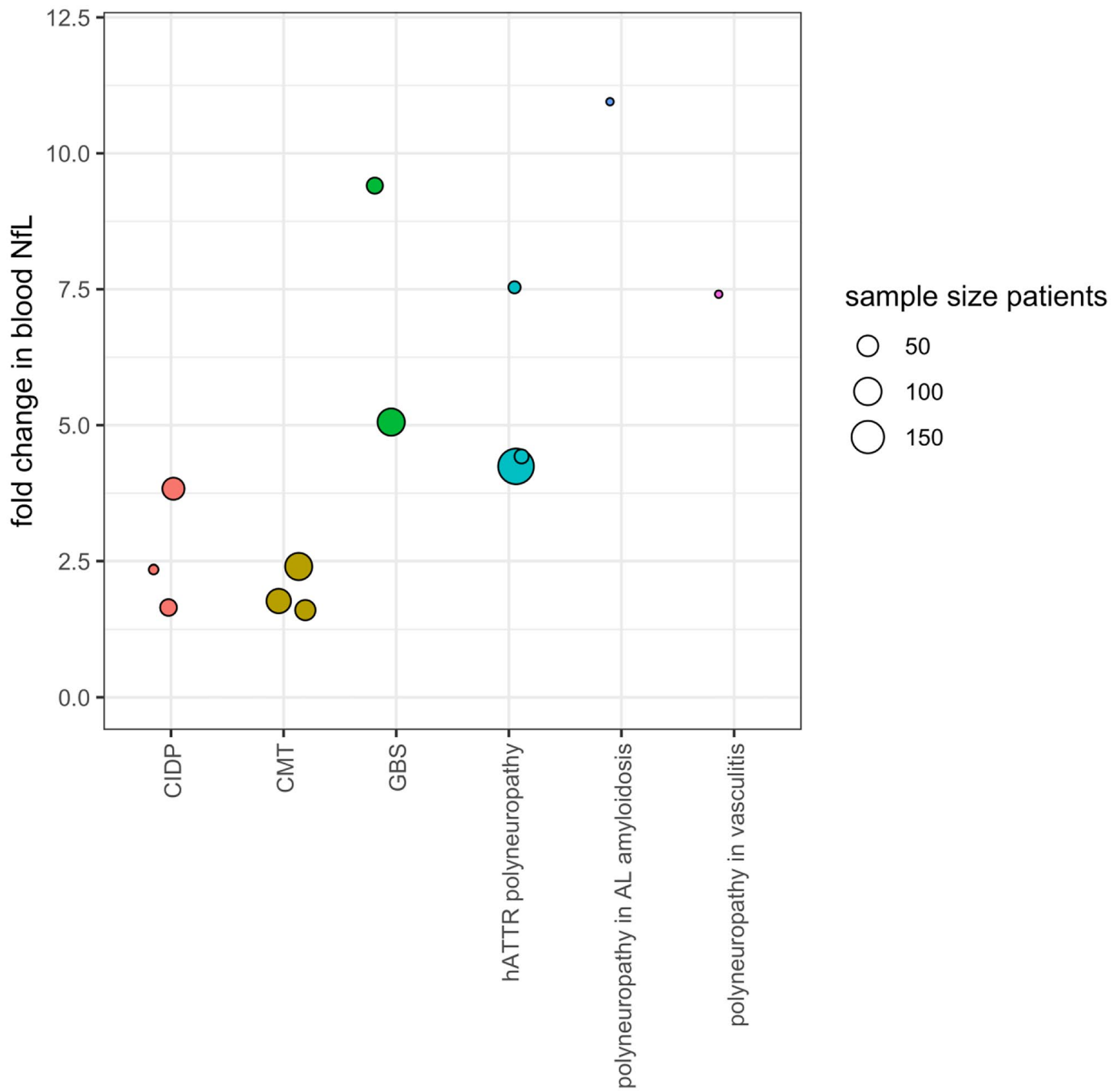

Fig. 1 Summary of fold change in blood NfL in various polyneuropathies. This figure displays the fold change in blood NfL levels when comparing patients to healthy controls. Values are presented in Table 1. When reported, patients with active disease were chosen for this comparison. CIDP, chronic inflammatory demyelinating polyneu-

specific enough to be diagnostic for particular disorders, as raised levels occur in many diseases including ALS, adrenoleukodystrophy, frontotemporal dementia, and autoimmune encephalitis. In clinical scenarios where the differential diagnosis includes disorders with differing degrees of axonal degeneration, NfL may be of diagnostic help, especially early after disease onset when clinical symptoms ropathy; CMT, Charcot-Marie Tooth disease; GBS, Guillain-Barré syndrome; hATTR, hereditary transthyretin-related amyloidosis. NB two studies were excluded from this figure because they presented as outliers: Körtveleyessy [74], which reports mean NfL values, and Gaiottino [75] which uses an ECL assay

can be limited. In a memory clinic, normal serum or CSF $\mathrm{NfL}$ in the 'worried well' can be reassuring of the lack of a neurodegenerative process [55]. Conversion to symptomatic ALS in genetic forms was shown to be preceded by a rise in NfL 12 months earlier [56]. The performance of NfL as a diagnostic biomarker in patients suspected of neuropathy has not been studied however. 


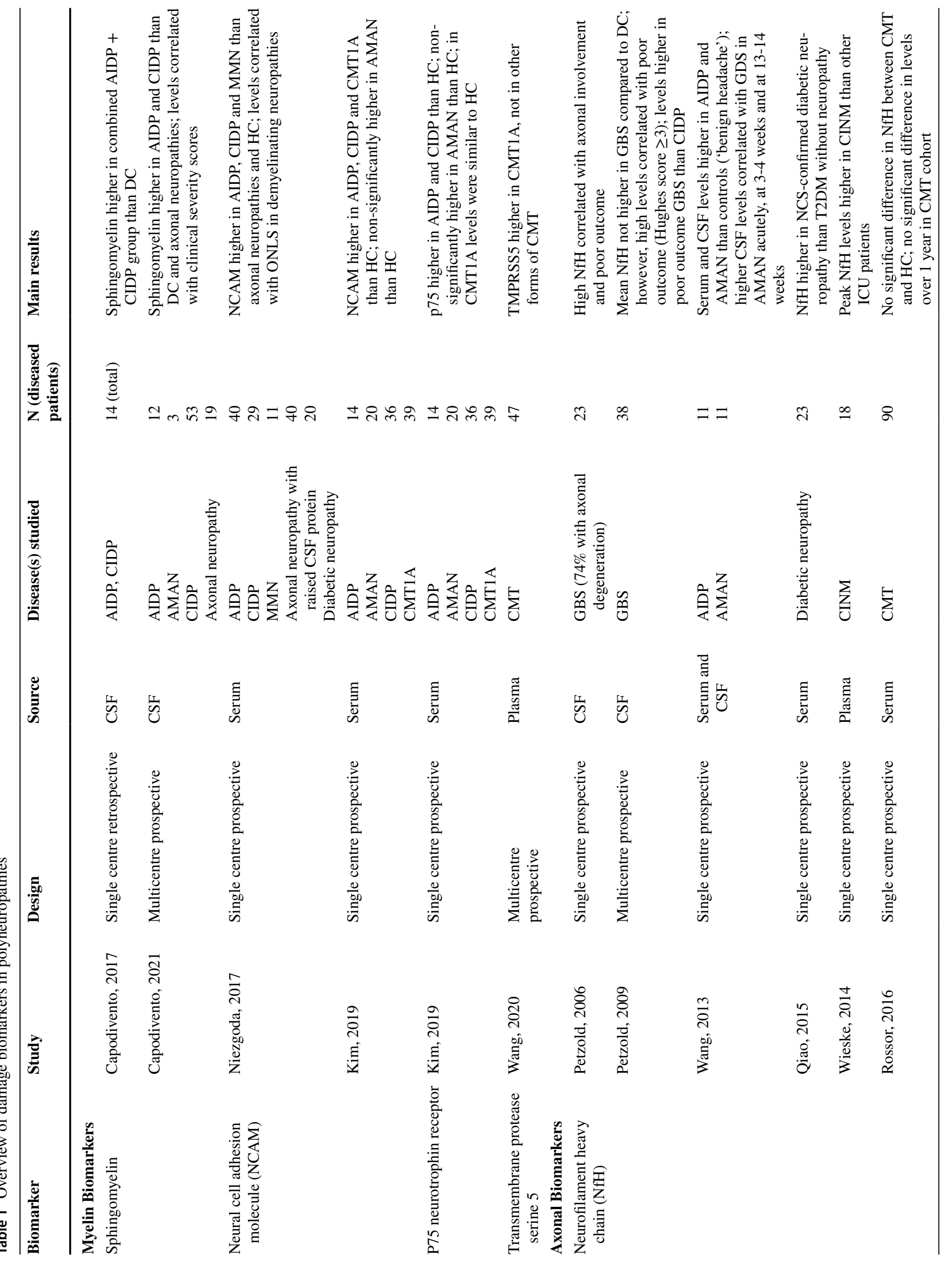




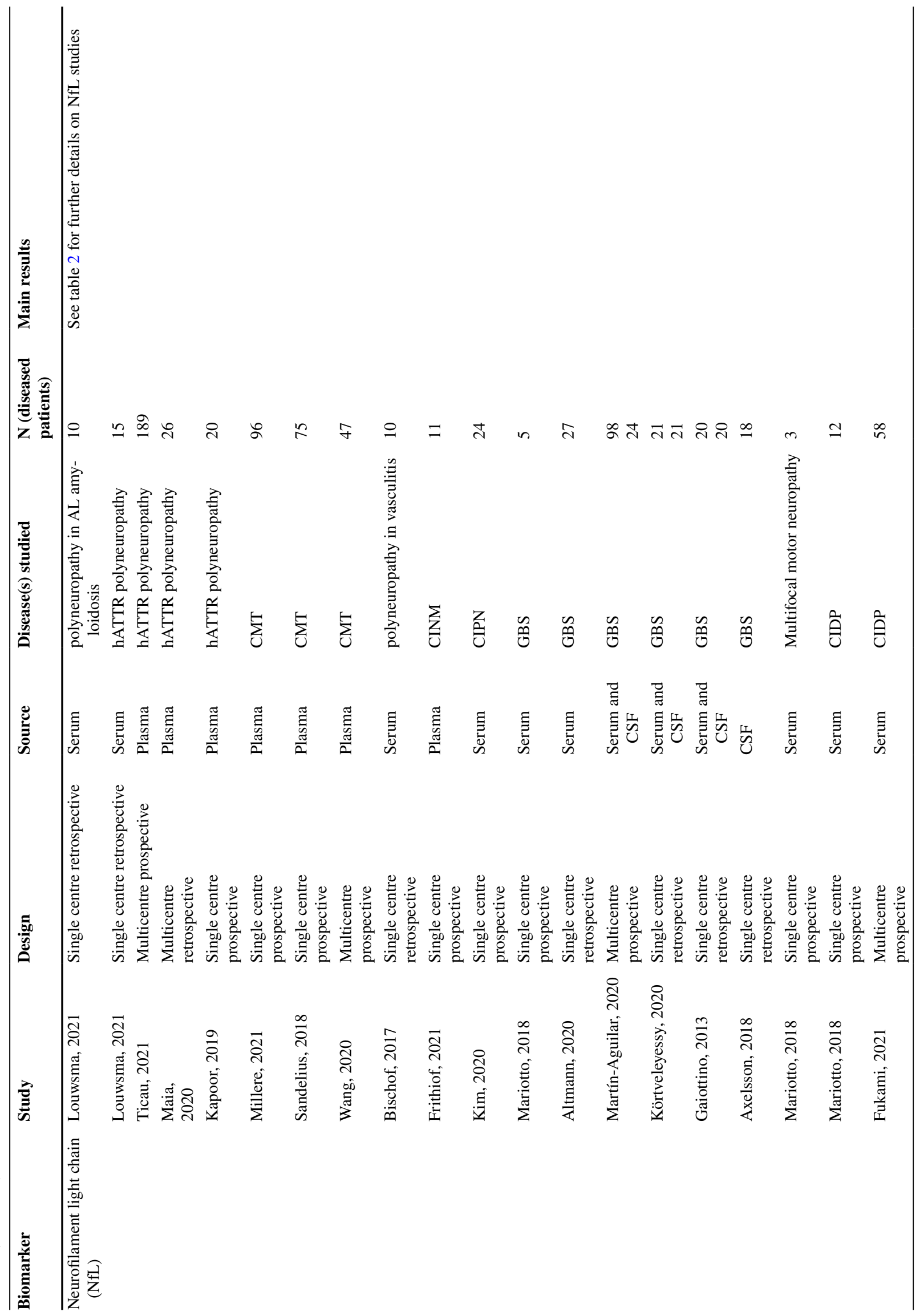




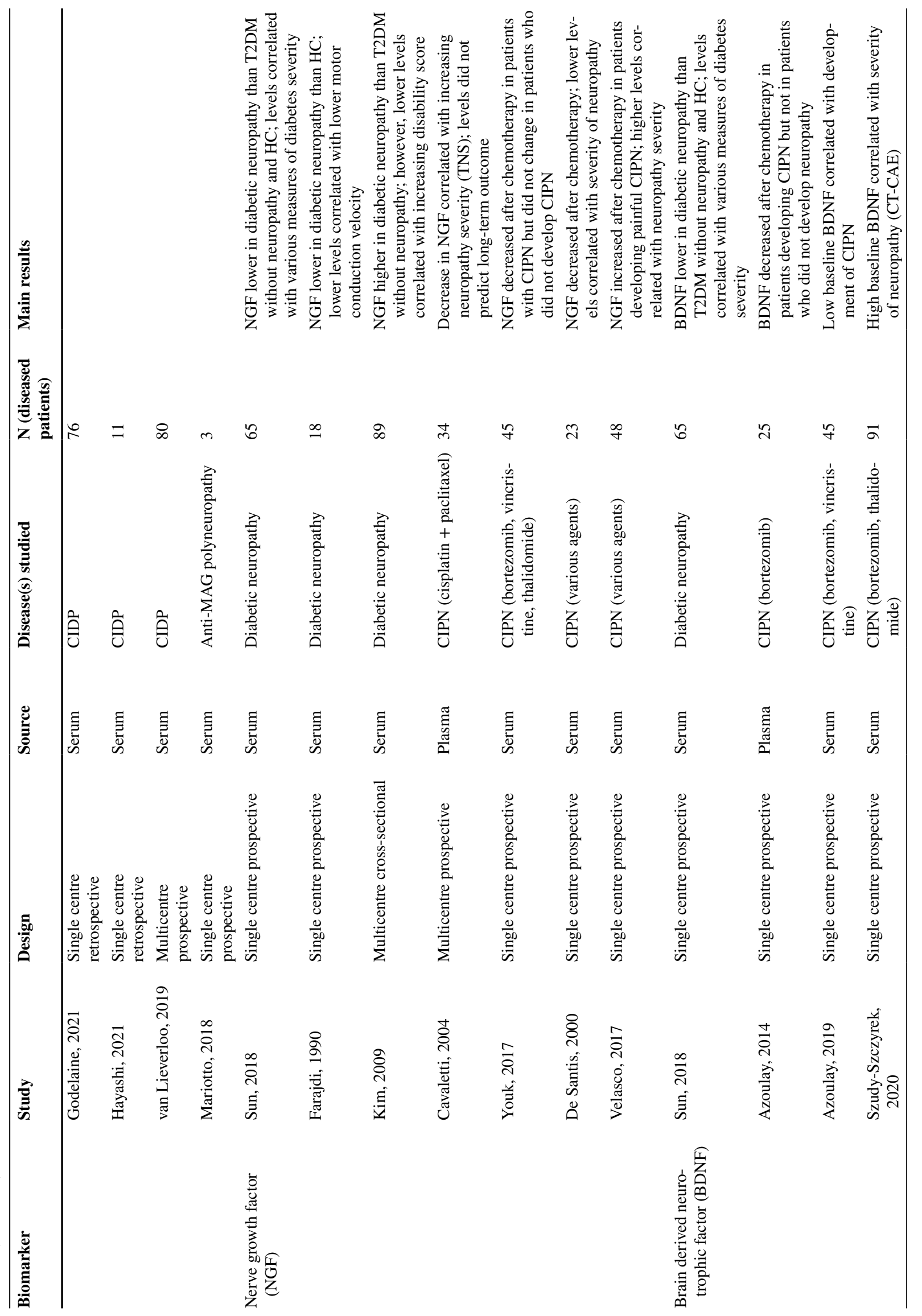




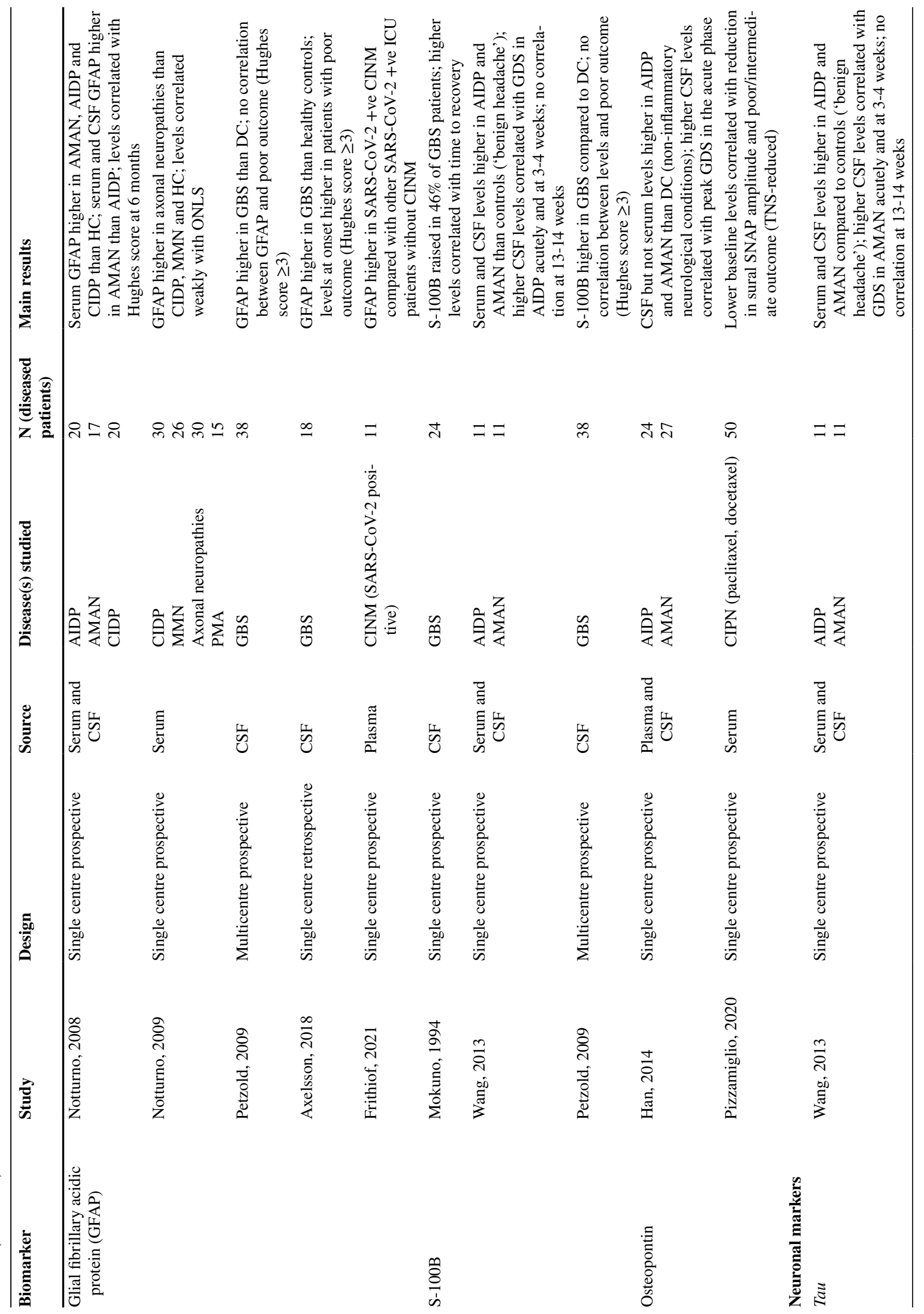




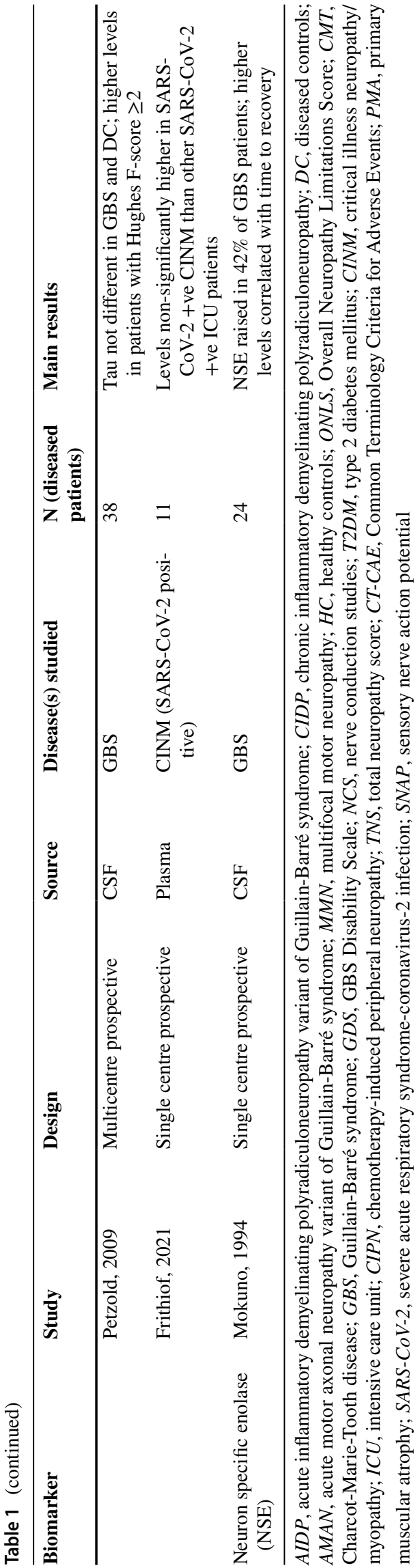

As with CNS disease, there are many potential applications such as assessing treatment efficacy and prognosis, identifying relapses of relapsing and remitting diseases such as CIDP, and differentiating the worried well from those with active disease. However, NfL has not yet found a place in clinical use despite potential in GBS, CIDP, and very promising findings in hATTR [53]. Arguably, the greatest clinical utility would be in optimizing treatment of patients to identify ongoing axonal damage that might become permanent before any clinical manifestation so that effective treatment might be applied. So far, in CIDP, such a clear differentiation has not been possible $[50,51,57]$. Moreover, it remains to be shown if $\mathrm{NfL}$ is the best marker to identify axonal damage early, when permanent sequelae may still be preventable, or whether other damage proteins released earlier in the cascade of axonal degeneration might be better.

\section{NfL in Clinical Trials}

Clinical trials are geared towards measuring clinically significant changes in outcome measures directly relating the therapeutic effect of an intervention to patient benefit in a reliable, reproducible, and unequivocal manner. In neuromuscular disease, measures of disability are favoured as meaningful to patients, and impairments as quantitatively measurable. However, neither relates directly to disease pathogenesis; quantifiable change may take time to develop; and as these measures are indirectly related to the pathology, they can be influenced by patient and measurement errors.

Some biological biomarkers have proven utility as outcomes in trials, such as muscle fat fraction MRI measurement in CMT1A which has excellent responsiveness and reliability in much shorter term assessments compared to clinical measures [58]. As NfL is directly linked to axonal damage, increases or decreases should be detectable acutely with worsening or with effective disease modifying interventions. This has already been shown in multiple sclerosis trials and, in polyneuropathies, only for hATTR neuropathy $[53,59]$.

Other biomarkers of Schwann cell or cell body damage, or perhaps immune activation, may be developed, possibly as compound measures in the future, and these may eventually become favoured for their directness. Until then, their inclusion as exploratory outcomes to prove their utility, explore responsiveness, correlate them to clinical change, and develop cut-off values will be important steps to them becoming accepted by regulatory authorities alongside traditional scales.

\section{Future}

Now that we have the technologies and analytical platforms, as well as increasing molecular knowledge, there is huge potential for biomarkers to become significant tools in diagnosis, therapeutics, and prognosis. 


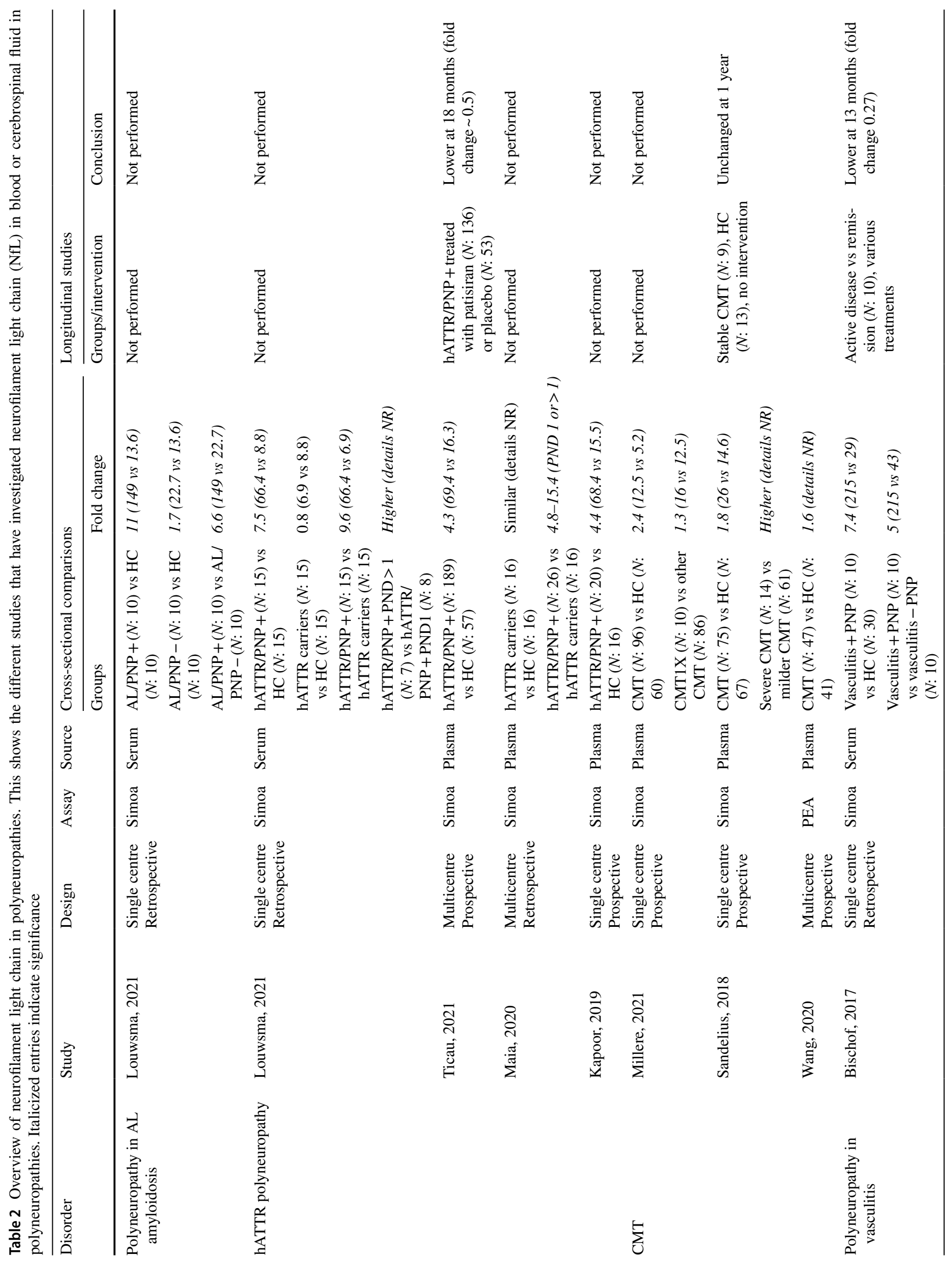




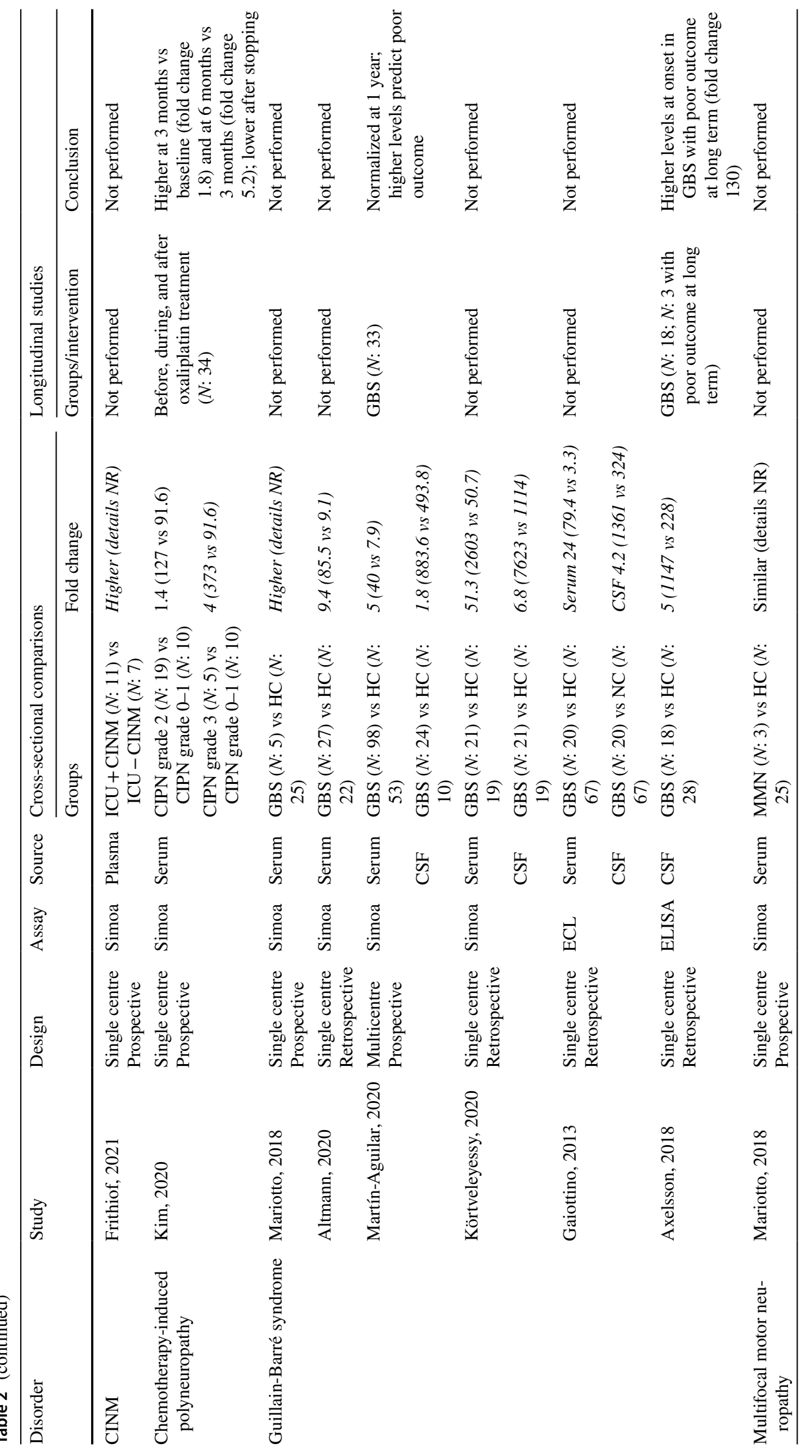




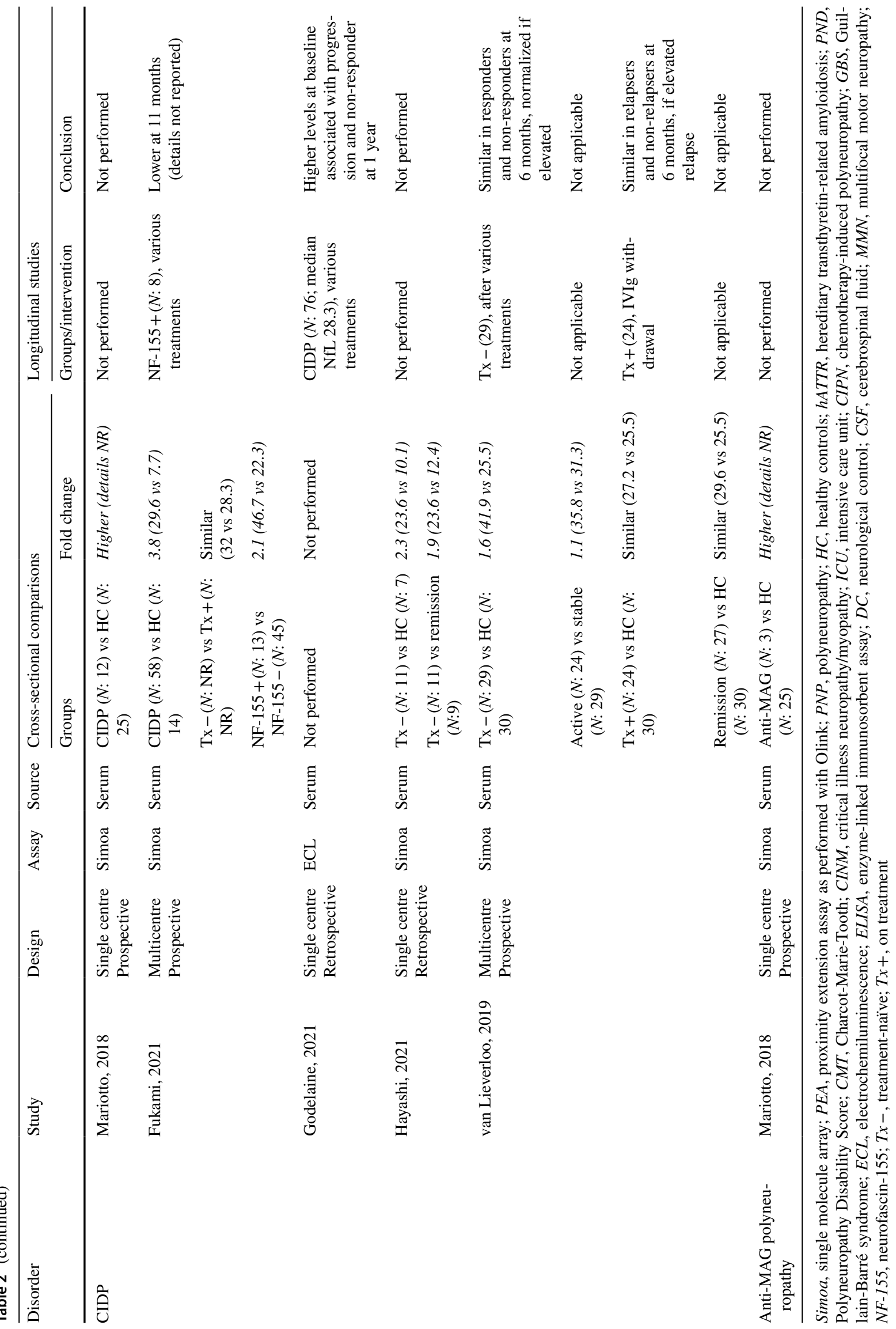


For biomarker identification, peripheral nerve diseases perhaps have some advantages over CNS diseases. Firstly, the lesser tissue mass and greater volume of distribution into which NfL is released might more reliably identify severe and acute damage. And arguably, more easily quantifiable clinical outcome measures of neuromuscular disease compared to CNS pathologies may correlate better with measured levels of a blood biomarker. Changes may occur more rapidly and reliably than clinical outputs resulting in better signal to noise in outcome measurement and possibly shorter trials, at least in early phases. However, the lack of a readily available tissue correlate and limitations of disability and impairment measures in discerning ongoing or residual axonal degeneration may form challenges to accurately anchor NfL levels and define meaningful changes in polyneuropathies.

Other protein biomarkers of damage to specific cell types, which differentiate CNS from PNS disease, that quantify blood-nerve barrier dysfunction and identify different pathway perturbations need to be identified and assays developed employing the novel technologies. It is likely that compound biomarkers utilizing two or more biomarkers in panels will be useful. Reaching from single protein measures into more complex pathway biomarkers has been explored in recent novel metabolomic [60-65] and epigenetic [66-70] approaches, where these techniques have sought to identify metabolic or microRNA 'fingerprints' in different neuropathies. It remains to be seen whether these will be clinically useful.

Besides more biomarkers, the best fluid compartment for measurement also needs to be explored. Blood-based analysis of molecules using ultrasensitive technologies offers advantages over CSF as samSpling is atraumatic and repeated samples are easily accessible giving better time resolution and more granular results. Urine and tears might also possible sources of measurable biomarkers in some cases.

Recently initiated international registries and biobanks, such as the International Guillain-Barré Syndrome Outcome Study (IGOS) [71], Inflammatory Neuropathy Consortium Base (INCbase) [72], and IgM Anti-MAG peripheral Neuropathy: from proper assessment to trial Needs (IMAGiNe) study [73], will allow collection of standardized clinical data and biomaterial of large numbers of patients that will surely speed up biomarker discovery in the next decade. Once biomarkers have been validated and rolled out for use, it will be important to unify technologies and institute quality control systems so assays remain reliable, standardized, and comparable from day to day and lab to lab. Providing core facilities for research and trials will help, but the funding for collaborative infrastructures will remain difficult to facilitate.
Supplementary Information The online version contains supplementary material available at https://doi.org/10.1007/s13311-021-01136-0.

Required Author Forms Disclosure forms provided by the authors are available with the online version of this article.

Open Access This article is licensed under a Creative Commons Attribution 4.0 International License, which permits use, sharing, adaptation, distribution and reproduction in any medium or format, as long as you give appropriate credit to the original author(s) and the source, provide a link to the Creative Commons licence, and indicate if changes were made. The images or other third party material in this article are included in the article's Creative Commons licence, unless indicated otherwise in a credit line to the material. If material is not included in the article's Creative Commons licence and your intended use is not permitted by statutory regulation or exceeds the permitted use, you will need to obtain permission directly from the copyright holder. To view a copy of this licence, visit http://creativecommons.org/licenses/by/4.0/.

\section{References}

1. Hanewinckel R, Drenthen J, van Oijen M, Hofman A, van Doorn PA, Ikram MA. Prevalence of polyneuropathy in the general middle-aged and elderly population. Neurology [Internet]. 2016;87:1892-8. Available from: http://www.neurology.org/ lookup/doi/10.1212/WNL.0000000000003293

2. Hanewinckel R, van Oijen M, Ikram MA, van Doorn PA. The epidemiology and risk factors of chronic polyneuropathy. Eur $\mathbf{J}$ Epidemiol [Internet]. 2016;31:5-20. Available from: http://link. springer.com/10.1007/s10654-015-0094-6

3. Telleman JA, Herraets IJT, Goedee HS, van Eijk RPA, Verhamme C, Eftimov F, et al. Prognostic value of nerve ultrasound: a prospective multicenter study on the natural history of chronic inflammatory neuropathies. Eur J Neurol [Internet]. 2021; ene.14885. Available from: https://onlinelibrary.wiley.com/doi/10.1111/ene.14885

4. FDA-NIH Biomarker Working Group. BEST (Biomarkers, EndpointS, and other Tools).

5. Siems SB, Jahn O, Eichel MA, Kannaiyan N, Wu LMN, Sherman DL, et al. Proteome profile of peripheral myelin in healthy mice and in a neuropathy model. Elife [Internet]. 2020;9. Available from: https://elifesciences.org/articles/51406

6. Capodivento G, De Michelis C, Carpo M, Fancellu R, Schirinzi E, Severi D, et al. CSF sphingomyelin: a new biomarker of demyelination in the diagnosis and management of CIDP and GBS. J Neurol Neurosurg Psychiatry [Internet]. 2021;92:30310. Available from: https://jnnp.bmj.com/lookup/doi/10.1136/ jnnp-2020-324445

7. Capodivento G, Visigalli D, Garnero M, Fancellu R, Ferrara MD, Basit A, et al. Sphingomyelin as a myelin biomarker in CSF of acquired demyelinating neuropathies. Sci Rep [Internet]. Springer US; 2017;7:7831. Available from: http://dx.doi.org/10.1038/ s41598-017-08314-1

8. Niezgoda A, Michalak S, Losy J, Kalinowska-Łyszczarz A, Kozubski W. sNCAM as a specific marker of peripheral demyelination. Immunol Lett [Internet]. 2017;185:93-7. Available from: https://linkinghub.elsevier.com/retrieve/pii/S0165247816302206

9. Kim YH, Kim YH, Shin YK, Jo YR, Park DK, Song M, et al. p75 and neural cell adhesion molecule 1 can identify pathologic Schwann cells in peripheral neuropathies. Ann Clin Transl Neurol [Internet]. 2019;6:1292-301. Available from: https://onlinelibrary. wiley.com/doi/10.1002/acn3.50828 
10. Wang H, Davison M, Wang K, Xia T, Kramer M, Call K, et al. Transmembrane protease serine 5: a novel Schwann cell plasma marker for CMT1A. Ann Clin Transl Neurol [Internet]. 2020;7:69-82. Available from: https://onlinelibrary.wiley.com/ doi/10.1002/acn3.50965

11. Petzold A, Hinds N, Murray NF, Hirsch NP, Grant D, Keir G, et al. CSF neurofilament levels: A potential prognostic marker in Guillain-Barre syndrome. Neurology [Internet]. 2006;67:1071-3. Available from: http://www.ncbi.nlm.nih.gov/pubmed/17000982

12. Petzold A, Brettschneider J, Jin K, Keir G, Murray NMF, Hirsch $\mathrm{NP}$, et al. CSF protein biomarkers for proximal axonal damage improve prognostic accuracy in the acute phase of Guillain-Barré syndrome. Muscle Nerve [Internet]. 2009;40:42-9. Available from: http://doi.wiley.com/10.1002/mus.21239

13. Wang X-K, Zhang H-L, Meng F-H, Chang M, Wang Y-Z, Jin T, et al. Elevated levels of S100B, tau and pNFH in cerebrospinal fluid are correlated with subtypes of Guillain-Barré syndrome. Neurol Sci [Internet]. 2013;34:655-61. Available from: http://link. springer.com/10.1007/s10072-012-1092-Z

14. Qiao X, Zhang S, Zhao W, Ye H, Yang Y, Zhang Z, et al. Serum Phosphorylated Neurofilament-Heavy Chain, a Potential Biomarker, is Associated With Peripheral Neuropathy in Patients With Type 2 Diabetes. Medicine (Baltimore) [Internet]. 2015;94:e1908. Available from: https://journals.lww.com/00005792-201511030-00030

15. Wieske L, Witteveen E, Petzold A, Verhamme C, Schultz MJMJ, van Schaik ININ, et al. Neurofilaments as a plasma biomarker for ICU-acquired weakness: an observational pilot study. Crit Care [Internet]. 2014 [cited 2014 Feb 21];18:R18. Available from: http://www.ncbi.nlm.nih.gov/pubmed/24443841

16. Rossor AM, Liu C-H, Petzold A, Malaspina A, Laura M, Greensmith $\mathrm{L}$, et al. Plasma neurofilament heavy chain is not a useful biomarker in Charcot-Marie-Tooth disease. Muscle Nerve [Internet]. 2016;53:9725. Available from: https://onlinelibrary.wiley.com/doi/10.1002/mus. 25124

17. Sun Q, Tang D-D, Yin E-G, Wei L-L, Chen P, Deng S-P, et al. Diagnostic Significance of Serum Levels of Nerve Growth Factor and Brain Derived Neurotrophic Factor in Diabetic Peripheral Neuropathy. Med Sci Monit [Internet]. 2018;24:5943-50. Available from: https://www.medscimonit.com/abstract/index/idArt/909449

18. Faradji V, Sotelo J. Low serum levels of nerve growth factor in diabetic neuropathy. Acta Neurol Scand [Internet]. 2009;81:4026. Available from: https://onlinelibrary.wiley.com/doi/10.1111/j. 1600-0404.1990.tb00984.x

19. Cavaletti G, Bogliun G, Marzorati L, Zincone A, Piatti M, Colombo N, et al. Early predictors of peripheral neurotoxicity in cisplatin and paclitaxel combination chemotherapy. Ann Oncol [Internet]. 2004;15:1439-42. Available from: https://linkinghub. elsevier.com/retrieve/pii/S0923753419460493

20. Youk J, Kim Y-S, Lim J-A, Shin D-Y, Koh Y, Lee S-T, et al. Depletion of nerve growth factor in chemotherapy-induced peripheral neuropathy associated with hematologic malignancies. Malik RA, editor. PLoS One [Internet]. 2017;12:e0183491. Available from: https://dx.plos.org/10.1371/journal.pone.0183491

21. De Santis S, Pace A, Bove L, Cognetti F, Properzi F, Fiore M, et al. Patients treated with antitumor drugs displaying neurological deficits are characterized by a low circulating level of nerve growth factor. Clin Cancer Res [Internet]. 2000;6:90-5. Available from: http://www.ncbi.nlm.nih.gov/pubmed/10656436

22. Azoulay D, Lavie D, Horowitz N, Suriu C, Gatt ME, Akria L, et al. Bortezomib-induced peripheral neuropathy is related to altered levels of brain-derived neurotrophic factor in the peripheral blood of patients with multiple myeloma. Br J Haematol [Internet]. 2014;164:454-6. Available from: https://onlinelibrary. wiley.com/doi/10.1111/bjh.12624

23. Azoulay D, Giryes S, Nasser R, Sharon R, Horowitz NA. Prediction of Chemotherapy-Induced Peripheral Neuropathy in Patients with Lymphoma and Myeloma: the Roles of Brain-Derived Neurotropic Factor Protein Levels and A Gene Polymorphism. J Clin Neurol [Internet]. 2019;15:511. Available from: https://www. thejen.com/DOIx.php?id=10.3988/jen.2019.15.4.511

24. Kim HC, Cho YJ, Ahn CW, Park KS, Kim JC, Nam JS, et al. Nerve growth factor and expression of its receptors in patients with diabetic neuropathy. Diabet Med [Internet]. 2009;26:122834. Available from: https://onlinelibrary.wiley.com/doi/10.1111/j. 1464-5491.2009.02856.x

25. Velasco R, Navarro X, Gil-Gil M, Herrando-Grabulosa M, Calls A, Bruna J. Neuropathic Pain and Nerve Growth Factor in Chemotherapy-Induced Peripheral Neuropathy: Prospective Clinical-Pathological Study. J Pain Symptom Manage [Internet]. 2017;54:815-25. Available from: https://linkinghub.elsevier.com/ retrieve/pii/S0885392417303536

26. Szudy-Szczyrek A, Mlak R, Bury-Kamińska M, Mielnik M, Podgajna M, Kuśmierczuk K, et al. Serum brain-derived neurotrophic factor (BDNF) concentration predicts polyneuropathy and overall survival in multiple myeloma patients. Br J Haematol [Internet]. 2020;191:77-89. Available from: https://onlinelibrary.wiley.com/doi/10.1111/bjh.16862

27. Notturno F, Caporale CM, De Lauretis A, Uncini A. Glial fibrillary acidic protein: A marker of axonal Guillain-Barrè syndrome and outcome. Muscle Nerve [Internet]. 2008;38:899-903. Available from: https://onlinelibrary.wiley.com/doi/10.1002/mus.20983

28. Notturno F, Capasso M, DeLauretis A, Carpo M, Uncini A. Glial fibrillary acidic protein as a marker of axonal damage in chronic neuropathies. Muscle Nerve. 2009;40:50-4.

29. Axelsson M, Sjögren M, Andersen O, Blennow K, Zetterberg H, Lycke J. Neurofilament light protein levels in cerebrospinal fluid predict long-term disability of Guillain-Barré syndrome: A pilot study. Acta Neurol Scand [Internet]. 2018;138:143-50. Available from: https://onlinelibrary.wiley.com/doi/10.1111/ane.12927

30. Petzold A, Rosengren L, Verbeek MM, Notturno F, Caporale CM, DeLauretis A, et al. Glial fibrillary acidic protein in GuillainBarré syndrome: Methodological issues. Muscle Nerve [Internet]. 2009;39:711-2. Available from: https://onlinelibrary.wiley.com/ doi/10.1002/mus.21283

31. Frithiof R, Rostami E, Kumlien E, Virhammar J, Fällmar D, Hultström M, et al. Critical illness polyneuropathy, myopathy and neuronal biomarkers in COVID-19 patients: A prospective study. Clin Neurophysiol [Internet]. International Federation of Clinical Neurophysiology; 2021;132:1733-40. Available from: https://doi. org/10.1016/j.clinph.2021.03.016

32. Steiner J, Bernstein H-G, Bielau H, Berndt A, Brisch R, Mawrin $\mathrm{C}$, et al. Evidence for a wide extra-astrocytic distribution of S100B in human brain. BMC Neurosci [Internet]. 2007;8:2. Available from: https://bmcneurosci.biomedcentral.com/articles/0.1186/ 1471-2202-8-2

33. Mokuno K, Kiyosawa K, Sugimura K, Yasuda T, Riku S, Murayama $\mathrm{T}$, et al. Prognostic value of cerebrospinal fluid neuron-specific enolase and S-100b protein in Guillain-Barré syndrome. Acta Neurol Scand [Internet]. 1994;89:27-30. Available from: http://www.ncbi.nlm.nih. gov/pubmed/8178624

34. Jander S, Bussini S, Neuen-Jacob E, Bosse F, Menge T, Müller H-W, et al. Osteopontin: A novel axon-regulated Schwann cell gene. J Neurosci Res [Internet]. 2002;67:156-66. Available from: https:// onlinelibrary.wiley.com/doi/10.1002/jnr.10099

35. Pizzamiglio C, Ripellino P, Prandi P, Clemente N, Saggia C, Rossi $\mathrm{V}$, et al. Nerve conduction, circulating osteopontin and taxaneinduced neuropathy in breast cancer patients. Neurophysiol Clin [Internet]. 2020;50:47-54. Available from: https://linkinghub. elsevier.com/retrieve/pii/S0987705319304241

36. Han R kun, Cheng Y feng, Zhou S shan, Guo H, He R dong, Chi L jun, et al. Increased Circulating Th17 Cell Populations and Elevated CSF Osteopontin and IL-17 Concentrations in Patients with Guillain-Barré Syndrome. J Clin Immunol [Internet]. 
2014;34:94-103. Available from: http://link.springer.com/10. 1007/s10875-013-9965-3

37. Day GS, Yarbrough MY, Körtvelyessy P, Prüss H, Bucelli RC, Fritzler MJ, et al. Prospective Quantification of CSF Biomarkers in Antibody-Mediated Encephalitis. Neurology [Internet]. 2021;96:e2546-57. Available from: http://www.neurology.org/ lookup/doi/10.1212/WNL.0000000000011937

38. Khalil M, Teunissen CE, Otto M, Piehl F, Sormani MP, Gattringer T, et al. Neurofilaments as biomarkers in neurological disorders. Nat Rev Neurol [Internet]. Springer US; 2018;14:577-89. Available from: http://www.ncbi.nlm.nih.gov/ pubmed/30171200

39. Kuhle J, Barro C, Andreasson U, Derfuss T, Lindberg R, Sandelius $\AA$, et al. Comparison of three analytical platforms for quantification of the neurofilament light chain in blood samples: ELISA, electrochemiluminescence immunoassay and Simoa. Clin Chem Lab Med [Internet]. 2016;54:1655-61. Available from: http://www.ncbi.nlm. nih.gov/pubmed/27071153

40. Bridel C, van Wieringen WN, Zetterberg H, Tijms BM, Teunissen CE, Alvarez-Cermeño JC, et al. Diagnostic Value of Cerebrospinal Fluid Neurofilament Light Protein in Neurology. JAMA Neurol [Internet]. 2019;76:1035. Available from: http://archneur. jamanetwork.com/article.aspx?doi=10.1001/jamaneurol.2019. 1534

41. Altmann P, Ponleitner M, Rommer PS, Haslacher H, Mucher $\mathrm{P}$, Leutmezer F, et al. Seven day pre-analytical stability of serum and plasma neurofilament light chain. Sci Rep [Internet]. 2021;11:11034. Available from: http://www.nature.com/articles/ s41598-021-90639-z

42. Ashton NJ, Suárez-Calvet M, Karikari TK, Lantero-Rodriguez J, Snellman A, Sauer M, et al. Effects of pre-analytical procedures on blood biomarkers for Alzheimer's pathophysiology, glial activation, and neurodegeneration. Alzheimer's Dement Diagnosis, Assess Dis Monit [Internet]. 2021;13:e12168. Available from: http://www.ncbi.nlm.nih.gov/pubmed/34124336

43. Keshavan A, Heslegrave A, Zetterberg H, Schott JM. Stability of blood-based biomarkers of Alzheimer's disease over multiple freeze-thaw cycles. Alzheimer's Dement Diagnosis, Assess Dis Monit [Internet]. 2018;10:448-51. Available from: https:// onlinelibrary.wiley.com/doi/abs/10.1016/j.dadm.2018.06.001

44. Huesgen KW, Elmelige YO, Yang Z, Chowdhury MAB, Gul S, Maciel CB, et al. Ultra-early serum concentrations of neuronal and astroglial biomarkers predict poor neurological outcome after out-of-hospital cardiac arrest-a pilot neuroprognostic study. Resusc Plus [Internet]. 2021;7:100133. Available from: http:// www.ncbi.nlm.nih.gov/pubmed/34223394

45. Bar-Or A. Blood neurofilament light levels are lowered to a healthy donor range in patients with RMS and PPMS following ocrelizumab treatment. ECTRIMS. 2019

46. Delcoigne B, Manouchehrinia A, Barro C, Benkert P, Michalak Z, Kappos L, et al. Blood neurofilament light levels segregate treatment effects in multiple sclerosis. Neurology [Internet]. 2020;94:e1201-12. Available from: http://www.neurology.org/ lookup/doi/10.1212/WNL.0000000000009097

47. Martín-Aguilar L, Camps-Renom P, Lleixà C, Pascual-Goñi E, Díaz-Manera J, Rojas-García R, et al. Serum neurofilament light chain predicts long-term prognosis in Guillain-Barré syndrome patients. J Neurol Neurosurg Psychiatry [Internet]. 2021;92:707. Available from: https://jnnp.bmj.com/lookup/doi/10.1136/ jnnp-2020-323899

48. Kim S-H, Choi MK, Park NY, Hyun J-W, Lee MY, Kim HJ, et al. Serum neurofilament light chain levels as a biomarker of neuroaxonal injury and severity of oxaliplatin-induced peripheral neuropathy. Sci Rep [Internet]. Springer US; 2020;10:7995. Available from: http://dx.doi.org/10.1038/s41598-020-64511-5
49. Fukami Y, Iijima M, Koike H, Yamada S, Hashizume A, Katsuno M. Association of serum neurofilament light chain levels with clinicopathology of chronic inflammatory demyelinating polyneuropathy, including NF155 reactive patients. J Neurol [Internet]. 2021; Available from: http://link.springer.com/10.1007/ s00415-021-10537-2

50. Hayashi T, Nukui T, Piao J, Sugimoto T, Anada R, Matsuda $\mathrm{N}$, et al. Serum neurofilament light chain in chronic inflammatory demyelinating polyneuropathy. Brain Behav [Internet]. 2021;11:187-94. Available from: https://onlinelibrary.wiley.com/ doi/10.1002/brb3.2084

51. Lieverloo GGA, Wieske L, Verhamme C, Vrancken AFJ, Doorn PA, Michalak Z, et al. Serum neurofilament light chain in chronic inflammatory demyelinating polyneuropathy. J Peripher Nerv Syst [Internet]. 2019;24:187-94. Available from: http://www.ncbi.nlm. nih.gov/pubmed/30973667

52. Bischof A, Manigold T, Barro C, Heijnen I, Berger CT, Derfuss $\mathrm{T}$, et al. Serum neurofilament light chain: a biomarker of neuronal injury in vasculitic neuropathy. Ann Rheum Dis [Internet]. 2018;77:1093-4. Available from: http://www.ncbi.nlm.nih.gov/ pubmed/28743789

53. Ticau S, Sridharan G V., Tsour S, Cantley WL, Chan A, Gilbert JA, et al. Neurofilament Light Chain as a Biomarker of Hereditary Transthyretin-Mediated Amyloidosis. Neurology [Internet]. 2021;96:e412-22. Available from: http://www.neurology.org/ lookup/doi/10.1212/WNL.0000000000011090

54. Abu-Rumeileh S, Parchi P. Cerebrospinal Fluid and Blood Neurofilament Light Chain Protein in Prion Disease and Other Rapidly Progressive Dementias: Current State of the Art. Front Neurosci [Internet]. 2021;15:1-9. Available from: https://www.frontiersin. org/articles/10.3389/fnins.2021.648743/full

55. Willemse EAJ, Scheltens P, Teunissen CE, Vijverberg EGB. A neurologist's perspective on serum neurofilament light in the memory clinic: a prospective implementation study. Alzheimers Res Ther [Internet]. Alzheimer's Research \& Therapy; 2021;13:101. Available from: https://alzres.biomedcentral.com/ articles/10.1186/s13195-021-00841-4

56. 56. Gaetani L, Parnetti L, Calabresi P, Di Filippo M. Tracing Neurological Diseases in the Presymptomatic Phase: Insights From Neurofilament Light Chain. Front Neurosci. 2021;15:1-7.

57. Godelaine J, De Schaepdryver M, Bossuyt X, Van Damme P, Claeys KG, Poesen K. Prognostic value of neurofilament light chain in chronic inflammatory demyelinating polyneuropathy. Brain Commun [Internet]. 2021;3:1-10. Available from: https:// academic.oup.com/braincomms/article/doi/10.1093/braincomms/ fcab018/6163280

58. Morrow JM, Evans MRB, Grider T, Sinclair CDJ, Thedens D, Shah $\mathrm{S}$, et al. Validation of MRC Centre MRI calf muscle fat fraction protocol as an outcome measure in CMT1A. Neurology [Internet]. 2018;91:e1125-9. Available from: http://www.neurology.org/ lookup/doi/10.1212/WNL.0000000000006214

59. Kuhle J, Disanto G, Lorscheider J, Stites T, Chen Y, Dahlke F, et al. Fingolimod and CSF neurofilament light chain levels in relapsing-remitting multiple sclerosis. Neurology [Internet]. 2015;84:1639-43. Available from: http://www.neurology.org/ cgi/doi/10.1212/WNL.0000000000001491

60. Park SJ, Kim JK, Kim H-H, Yoon B-A, Ji DY, Lee C-W, et al. Integrative metabolomics reveals unique metabolic traits in Guillain-Barré Syndrome and its variants. Sci Rep [Internet]. 2019;9:1077. Available from: http://www.nature.com/articles/ s41598-018-37572-w

61. Visigalli D, Capodivento G, Basit A, Fernández R, Hamid Z, Pencová B, et al. Exploiting Sphingo- and Glycerophospholipid Impairment to Select Effective Drugs and Biomarkers for CMT1A. Front Neurol [Internet]. 2020;11. Available from: https://www.frontiersin.org/article/10.3389/fneur.2020.00903/full 
62. Kramer R, Bielawski J, Kistner-Griffin E, Othman A, Alecu I, Ernst D, et al. Neurotoxic 1-deoxysphingolipids and paclitaxel-induced peripheral neuropathy. FASEB J [Internet]. 2015;29:4461-72. Available from: https://onlinelibrary.wiley. com/doi/10.1096/fj.15-272567

63. Verma P, Devaraj J, Skiles JL, Sajdyk T, Ho RH, Hutchinson R, et al. A Metabolomics Approach for Early Prediction of Vincristine-Induced Peripheral Neuropathy. Sci Rep [Internet]. 2020;10:9659. Available from: http://www.nature.com/articles/ s41598-020-66815-y

64. Sun Y, Kim JH, Vangipuram K, Hayes DF, Smith EML, Yeomans L, et al. Pharmacometabolomics reveals a role for histidine, phenylalanine, and threonine in the development of paclitaxel-induced peripheral neuropathy. Breast Cancer Res Treat [Internet]. 2018;171:657-66. Available from: http://link.springer.com/10.1007/s10549-018-4862-3

65. Maekawa K, Ri M, Nakajima M, Sekine A, Ueda R, Tohkin M, et al. Serum lipidomics for exploring biomarkers of bortezomib therapy in patients with multiple myeloma. Cancer Sci [Internet]. 2019;110:3267-74. Available from: https://onlinelibrary. wiley.com/doi/10.1111/cas.14178

66. Vita GL, Aguennouz M, Polito F, Oteri R, Russo M, Gentile L, et al. Circulating microRNAs Profile in Patients With Transthyretin Variant Amyloidosis. Front Mol Neurosci [Internet]. 2020;13. Available from: https://www.frontiersin.org/article/10. 3389/fnmol.2020.00102/full

67. Fan B, Chopp M, Zhang ZG, Liu XS. Emerging Roles of microRNAs as Biomarkers and Therapeutic Targets for Diabetic Neuropathy. Front Neurol [Internet]. 2020;11. Available from: https://www.frontiersin.org/articles/10.3389/fneur.2020. 558758/full

68. Peng Q, Mechanic J, Shoieb A, Pardo ID, Schaevitz L, FenykMelody J, et al. Circulating microRNA and automated motion analysis as novel methods of assessing chemotherapy-induced peripheral neuropathy in mice. Borchelt DR, editor. PLoS One [Internet]. 2019;14:e0210995. Available from: https://dx.plos. org/10.1371/journal.pone.0210995

69. Noda-Narita S, Shimomura A, Tanabe Y, Kawauchi J, Matsuzaki J, Takizawa $\mathrm{S}$, et al. Peripheral neuropathy from paclitaxel: risk prediction by serum microRNAs. BMJ Support Palliat Care [Internet]. 2020;bmjspcare-2019-001900. Available from: https://spcare.bmj. com/lookup/doi/10.1136/bmjspcare-2019-001900
70. Wang H, Davison M, Wang K, Xia T-H, Call KM, Luo J, et al. MicroRNAs as Biomarkers of Charcot-Marie-Tooth Disease Type 1A. Neurology [Internet]. 2021;97:e489-500. Available from: http://www.ncbi.nlm.nih.gov/pubmed/34031204

71. Jacobs BC, van den Berg B, Verboon C, Chavada G, Cornblath DR, Gorson KC, et al. International Guillain-Barré Syndrome Outcome Study: protocol of a prospective observational cohort study on clinical and biological predictors of disease course and outcome in Guillain-Barré syndrome. J Peripher Nerv Syst [Internet]. 2017;22:68-76. Available from: https://onlinelibrary. wiley.com/doi/10.1111/jns.12209

72. Eftimov F, Bunschoten C, Rajabally Y, Querol L, participants of the 231st ENMC workshop. 231st ENMC International Workshop:: International Standard for CIDP Registry and Biobank, Naarden, The Netherlands, 12-14 May 2017. Neuromuscul Disord [Internet]. 2018;28:178-84. Available from: http://www.ncbi.nlm.nih. gov/pubmed/29305135

73. Pruppers MHJ, Merkies ISJ, Lunn MPT, Notermans NC, IMAGiNe Study Group. 230th ENMC International Workshop:: Improving future assessment and research in IgM anti-MAG peripheral neuropathy: A consensus collaborative effort, Naarden, The Netherlands, 24-26 February 2017. Neuromuscul Disord [Internet]. 2017;27:1065-72. Available from: https://linkinghub.elsevier. com/retrieve/pii/S0960896617312087

74. Körtvelyessy P, Kuhle J, Düzel E, Vielhaber S, Schmidt C, Heinius $\mathrm{A}$, et al. Ratio and index of Neurofilament light chain indicate its origin in Guillain-Barré Syndrome. Ann Clin Transl Neurol [Internet]. 2020;7:2213-20. Available from: https://onlinelibrary.wiley. $\mathrm{com} / \mathrm{doi} / 10.1002 / \mathrm{acn} 3.51207$

75. Gaiottino J, Norgren N, Dobson R, Topping J, Nissim A, Malaspina A, et al. Increased Neurofilament Light Chain Blood Levels in Neurodegenerative Neurological Diseases. Reindl M, editor. PLoS One [Internet]. 2013;8:e75091. Available from: https://dx.plos.org/10.1371/journal.pone.0075091

Publisher's Note Springer Nature remains neutral with regard to jurisdictional claims in published maps and institutional affiliations. 